\section{Psychotherapy, learning disabilities and trauma: new perspectives ${ }^{\dagger}$}

\author{
SHEILA HOLLINS and VALERIE SINASON
}

An estimated 300000 children and adults with severe learning disabilities live in the UK, and over 1000000 have a mild learning disability. The majority of the latter live in relative poverty (Office of Population Censuses and Surveys, 1989). Many people have coexisting physical disabilities and, not surprisingly given the burden they carry, there is an increase in emotional disturbance in proportion to the severity of the learning disability.

However, there is a tendency to ascribe the emotional difficulties experienced by the individual to the disability rather than to emotional state or needs. "My sister has a tantrum and they say she is cross because she doesn't get enough pocket money. I get cross and they phone the psychiatrist", commented a learning disabled young man.

Current definitions of learning disability point to the importance of holistic approaches to understanding individual need which look at several aspects of a person's functioning within the context of their own life and relationships (World Health Organization, 1992).

Many people with learning disabilities have personality attributes and other qualities which contribute to a fulfilling life in spite of their impairments. Many others experience secondary emotional disabilities which interfere with their adjustment to life and their enjoyment of it (Sinason, 1986), and which may be symptomatic of the trauma of the original impairment.

In this paper we start by reviewing the availability of different psychotherapeutic approaches to addressing emotional and mental health problems in people with learning disabilities. Key developmental issues such as attachment formation, sexuality and mortality are examined in relation to the experiences of people with learning disabilities. Then, the experience of trauma by people with learning disabilities, and a psychotherapeutic approach to its management are explored.

\section{AVAILABILITYOF PSYCHOLOGICALTHERAPIES}

Despite the encouraging rise of creative therapies (Heal, 1989), group treatment (Hollins \& Evered, 1990) individual therapy (Sinason, 1992) and family therapy (Goldberg et al, 1995), treatment for children and adults with learning disabilities who experience emotional problems is still inadequate. Indeed, in isolating one major area of concern, namely self-injury, Oliver et al (1987) found that of 596 self-injuring children and adults, only 12 were receiving any psychological treatment, and only one received psychoanalytic psychotherapy. However, there are promising findings from outcome studies that psychodynamic treatment reduces emotional problems and symptoms (Sigman, 1985; Frankish, 1989; Beail, 1995; Bichard et al, 1996).

A review of behavioural interventions in learning disability by Scotti et al (1991) found that they were mainly single case studies. Cognitive-behavioural therapy (CBT) has made a significant contribution to the treatment of mental health problems in the general population (such as with traumatised groups, in depression, and following abuse), and is now being developed in practice with people with learning disabilities. Lindsay (1999) discusses data for more than 50 people with moderate learning disabilities; the data show a lasting clinical effect of treatment designed to change their cognitions. Recently, cognitive-behavioural approaches have been developed to enable parents of disabled children to change unhelpful cognitive attribution patterns (Turk, 1998) and to adopt more effective coping strategies.

\section{DEVELOPMENTAL ISSUES}

Regardless of the level of learning disability the following shared psychic organising principles will have to be dealt with: the existence of the disability itself (including the conscious and unconscious fantasies that accompany it); loss (of the normal self who would have been born); sexuality (internally distorted by the impact of the disability); dependency (not being able to live autonomously); and fear of death or murder (being part of a group that society wishes to eliminate). These areas will be illustrated from clinical perspectives. 


\section{Diagnosis of learning disability - the family's response}

At the birth of a disabled child many parents experience something akin to grief for the perfect child who was expected. Recent studies of the effects on attachment of an early diagnosis of learning disability suggest that attachment is more likely to be insecure (Esterhuyzen \& Hollins, 1997). The long-term consequences for people with learning disabilities of insecure maternal attachment probably bear similarities to those (such as separation difficulties) described by attachment researchers (De Zulueta, 1993; Main, 1996; Sausse, 1996), but may also include challenging behaviour and pathological grief following significant losses (Hollins \& Esterhuyzen, 1997).

\section{Attachment}

Childhood attachment is a prerequisite of safety. Attachment to an adult or adults protects children from danger while they develop the maturational skills to care for themselves. Where a parent is unable to screen a child from danger, or is part of a dangerous experience for a child, the child's perception of safety and of adult protectiveness can be altered or destroyed (Pynoos $e t$ al, 1995).

Spitz (1983) found that in an orphanage where hygiene was impeccable, toddlers who had no attachment figures were more susceptible to illness and had higher mortality rates. The infants started becoming 'retarded' at three months, when weaning occurred and the 'modest human contacts' they had were stopped. Some were given a better environment in their second year of life but "notwithstanding this improvement in environmental conditions, the process of deterioration proved to be progressive". Spitz (1983) described how children faced with a long period of deprivation "offer pictures reminiscent of brain-damaged individuals, of severely retarded or downright imbecile children".

We raise the question of whether this infantile depression also accounts for the visual appearance of some learning disabled children. Moreover, we consider that where there is disruption to bonding as a result of the disability, the disability itself is experienced as a trauma, both at the time it is diagnosed for the parents and at the time the child becomes cognitively aware of it.

\section{Dependence and disability in adulthood}

The extra needs of some disabled teenagers make it more difficult for them to take the first steps towards adult life. Many parents also experience difficulty in letting go of their disabled adult son or daughter, perhaps because of the distorting effect on parental psychopathology of caring for a child with different needs (Hubert, 1991).

Both CBT and psychodynamic therapy can help people to look at the internalexternal dimension in their lives, and try to reconcile their inner world with the external reality which other people see. A pilot repertory grid study was conducted by one author (S.H.) with young adults with learning disabilities in group therapy. The pre-treatment grids showed a larger than expected difference between ratings for real self and ideal self. In the first year of treatment, this gap widened for some members as they confronted the reality of their learning disabilities. Most of them succeeded in closing the gap as treatment progressed (Hollins \& Evered, 1990).

\section{Sexuality}

Sexual development occurs over the same period of time in everyone, but people with learning disabilities may receive contradictory messages about certain basic sexual matters, and also about the appropriateness or inappropriateness of their behaviour. Developing their sexual identity, and achieving the transitions from childhood to adolescence and from adolescence to adulthood, are more difficult than for those without learning disability (Sigman, 1985). Little help is available to prepare the young person with learning disability to have an intimate relationship or to plan to get married. This is an area of ambiguity for staff and, even more, for their clients.

However, we know that sexual abuse of children and adults with learning disabilities is more common than it is in the rest of the population (Turk \& Brown, 1993), and that some of the 'victims' later become perpetrators of abuse. If spoken language skills are limited, it may be difficult to communicate the emotional feelings of emerging sexuality or those associated with sexual experience or sexual abuse.

\section{Mortality}

There is evidence that concepts of the universality, inevitability and irreversibility of death are acquired later than usual in people with learning disabilities (Harper $\&$ Wadsworth, 1993). These concepts are not made easier to acquire by exclusion from the more concrete aspects of death and death rituals.

\section{Clinical vignette}

Three years after her husband's death, a widow was still telling her daughter that Daddy had gone to work. Her daughter had had respite care during the funeral rituals and had not shared in the family grieving. Later, there were no rituals or grieving visitors that could help her daughter to understand or to express her feelings of loss. Her repetitive questioning, 'where is Dad?', could easily have been misperceived as echolalia, and considered inappropriate. The mother hoped to protect her daughter from the reality of her loss and assumed that she would not be deeply affected by something which is so difficult to explain.

\section{Psychopathology of grief}

In a study of parentally bereaved adults with learning disabilities, only about half were known to have attended the funeral of a deceased parent (Hollins \& Esterhuyzen, 1997). As a group the bereaved subjects demonstrated more psychopathology and behavioural disturbance, including irritability, anxiety, adjustment difficulties and depression, than the controls. Nearly threequarters of their carers did not attribute any behavioural change to the bereavement. Most of us need time, perhaps many months, to grieve after a death; follow-up of the above subjects after five years (Bonell-Pascual et al, 1999) pointed to the likelihood of delayed and/or prolonged grief in many people with learning disabilities, particularly those who had not had a bereavement-related intervention.

\section{The fear of annihilation}

The unconscious fear of annihilation is exacerbated in people with learning disabilities as a result of their facing societal and personal death-wishes (Sinason, 1992). For example, the casual mention of amniocentesis or abortion on television or radio may have a traumatic impact, because it may awaken in the disabled person the awareness that he or she might have been 'discarded' as a result of these procedures. Compliance, excessive 'smiling' of a false kind, violence, and 
withdrawal may be different responses to this fear.

\section{Clinical vignette}

A 40-year-old woman with autism lost three stone in weight, and seemed to have lost the will to live. Her mother's brother had died two years earlier, and her elderly parents were in poor health. They would not make any plans for her future as, in common with some other older parents, they were hoping that she would die before them. Family therapy sessions were effective in reaching a new family view of her life opportunities and the importance to her of concrete plans being made for her future.

\section{TRAUMA}

A separate category for psychological trauma was first added to the Diagnostic and Statistical Manual of Mental Disorders in 1980 for adults and in 1987 for children (American Psychiatric Association, 1980, 1987). To have experienced a trauma, "a person must have experienced an event that is outside the range of usual human experience and that would be markedly distressing to almost anyone, such as a serious threat or harm to one's life or physical integrity" (DSM-III; American Psychiatric Association, 1980).

In addition to definitions of trauma that include destruction of one's home or community, or witnessing violence, we suggest that some components apply to the experience of disability.

The current criteria for a traumatic event in DSM-IV (American Psychiatric Association, 1994) add that "the person's response involves intense fear, helplessness, or horror. In children this may be expressed instead by disorganised or agitated behaviour". Suddenness is an intrinsic component of a traumatic incident. The discovery of a baby's impairment, whether by amniocentesis, a scan or indeed at birth, has that characteristic of suddenness.

\section{Post-traumatic stress disorder}

Central to the experience of post-traumatic stress disorder for both children and adults is the re-experiencing of the trauma through flashbacks, recurrent intrusive distressing recollections, traumatic play, dreams and nightmares of the event, behavioural re-enactments, and psychological and physiological responses to triggers of the event. Avoidance and numbing of general responsiveness are prevalent, as are memory distortions, omissions or dissociative reactions. Symptoms of increased arousal include hypervigilance, startle reactions, sleep disturbance and inability to concentrate. The presence of past trauma in the present can be understood by Freud's (1893) concept that the psychical trauma, or rather the memory of it, is a "foreign body which long after its entry must continue to be regarded as an agent that is still at work".

\section{Clinical vignette to illustrate the impact of trauma}

This vignette is drawn from a weekly psychoanalytic group run by the authors for men with moderate learning disabilities (IQ 45-65) who show inappropriate sexual behaviour. This extract is from a session three years after treatment began and three weeks before a Christmas break. Patient details have been changed to avoid recognition. Group members gave verbal consent to the reporting of a session.

Mr A.

(wringing his hands, very physically agitated) I am upset I am. Very upset. It happened last night. I wet myself. I could not help it. She rubbed my nose in the urine. She hit me. She did. She hit me. She rubbed my nose in it. (His despair and agitation built up. We were both aware that this had been a regular occurrence in his past but did not take place in his current placement.)

V.S.

I wonder if, because Mr A. is so miserable with Xmas coming, he is remembering something from the past that used to happen, but he feels it is happening now. (Mr A. stopped wringing his hands and sat still, listening.)

S.H.

Did you understand that, Mr A.? V.S. says that when you think about what your mum used to do, it feels as if it is happening now.

Mr A.

I know. Yes.

Mr B.

I phoned my mum at I a.m. She was cross about it. I rang because I was paranoid.

S.H.

What does paranoid mean?

Mr B.

I thought people knew more about me than they did - like the police might come and ask about something and I hadn't done it.

V.S.

You and Mr A. have got something in common that helps the whole group. In the past, bad things have happened for both of you - things other people did to you and things you did. For example, Mr B., sometimes the police came and it was fair, and sometimes you did not think it was fair - and perhaps, most frighteningly of all, sometimes the police came and there was evidence but you had no memory of doing it.

Mr B.

Yes. That's right.

V.S.

And in those cases the police did know more than you.

Mr B.

You mean - I am not paranoid because sometimes the police do know more than me?

Mr A.

I am going to miss my mum at $X$ mas. Really miss her.

S.H.

The magic has really gone out of $X$ mas, hasn't it?

Mr D.

Yes. No champagne or rides in a Rolls-Royce to group therapy.

Mr E.

My mum won't have any beer at $X$ mas because of fighting.

V.S.

And Mr C. hasn't got a mum to see - he hasn't seen her since he was really little and he has no idea where she is; and $\mathrm{Mr} A$. doesn't see his mum; and Mr B.'s mum doesn't want to be woken up at I. a.m. when he is anxious; and S.H. and I are bad mothers not looking after you all at Xmas. And perhaps, Mr B. you are worried that if you move nearer your mum she won't manage to help you.

Mr A.

I am not going to my mother's. I used to run away to get to her. I used to run away to find her. My mother can decide if I stay with her - no-one else. (He gets agitated again.)

S.H.

I think you are frightened, Mr A. that when your hospital closes down you might have to be with your mum, who did not look after you? But that won't happen. You will be in another safe place. (A sigh of relief passed around the group.)

Mr B.

We don't have magic about $\mathrm{X}$ mas any more.

V.S.

You are pleased there will be ward parties, but also you are sad, and when you're sad, or sad and angry, all the bad memories come back.

Mr A.

Yes.

We consider that traumatic symptoms are significantly under-recognised in people with learning disabilities. This short extract shows how earlier trauma was expressed through flashbacks for one 
man, and through an incomplete memory for another.

\section{DISCUSSION}

\section{Understanding the mental health needs of people with learning disabilities}

Historically, there has been a profound inability to consider that the individual with learning disabilities has any emotional skills with which to consider his or her predicament. We consider that the existence of learning disability evokes primitive fears and fantasies societally concerning damage, guilt and loss. Some of the guilt may be due to societal disadvantages.

Emotional distress or mental illness may be disguised or expressed in ways rather different from the norm, typically behaviourally. In order to make connections between feelings and behaviour, experience and skill are required to put into words what someone cannot say for themselves, along with a willingness to see whether the person can understand more than they can communicate in words. In particular, the important role of past trauma in shaping a person's interpersonal behaviour has been highlighted in this paper. We should remember that the existence of disability at birth impacts on the relationship of the individual with their family and community.

\section{The clinician's role}

Psychiatrists and other mental health professionals have a role in understanding the continuum between social care and health care, and in promoting healthy lifestyles which support good mental health. Mental health assessments and interventions must focus not just on the individual, but also on the context within which an individual lives his or her life.

\section{Service developments}

More specialist psychological therapy services for people with learning disabilities including CBT, family therapy and psychodynamic therapies, are being developed in the UK along the lines recommended by the National Health Service Review of Psychotherapy (Parry, 1993). The Royal College of Psychiatrists has established a multidisciplinary working group to review some training issues concerning psychotherapy and people with learning disabilities.

\section{CLINICAL IMPLICATIONS}

- Ongoing clinical audit using standard outcome measures should be part of learning disability psychotherapy service protocols.

Psychotherapy training and supervision should be made available to health and social care practitioners in the learning disability field.

Clinicians should be alert to the possible role of past trauma in shaping current interpersonal behaviour.

\section{LIMITATIONS}

Limited quantitative research evidence is available.

- This review is too short to do justice to the available literature on patient and therapist experience.

- We focused mainly on psychoanalytic theoretical and clinical issues, rather than the full range of therapeutic approaches.

SHEILA HOLLINS, FRCPsych, VALERIE SINASON, BPAS, Department of Psychiatry of Disability, St George's Hospital Medical School, London

Correspondence: Professor Sheila Hollins, St George's Hospital Medical School, Department of Psychiatry of Disability, Jenner Wing, Cranmer Terrace, London SWI7 0RE. Tel: 0208725 550I ; Fax: 020 8672 1070; e-mail: s.hollins@sghms.ac.uk

(First received 12 July 1999, final revision 20 September 1999, accepted 2I September 1999)

However, therapy is likely to remain a rare provision for the foreseeable future.

\section{Training}

Education for health and social care professionals about the emotional needs of people with learning disabilities should be made widely available, and psychiatrists should inform this agenda. Professionals in the multi-disciplinary team would be enriched by understanding and applying the core concepts of CBT (Kroese et al, 1997). The need for parental counselling as part of early intervention following diagnosis of learning disability is reinforced by recent attachment research; such counselling could be part of the repertoire of health visitors and focus on primary care-givers. Learning disability social workers and community nurses could train as bereavement counsellors and intervene appropriately at times of loss in order to ensure inclusion and facilitate grieving. However, more specialist training opportunities need to be developed in order to make psychoanalytic psychotherapy available to people with learning disabilities.

\section{Future research}

Clinical audit using standard outcome measures should be part of learning disability psychotherapy service protocols.

Research is needed to look at predictors of outcome in terms of patient characteristics, and to help practitioners focus their therapeutic effort as effectively as possible. However, process research will also be valuable in helping us to understand more about the impact of learning disabilities on individuals and families.

\section{REFERENCES}

American Psychiatric Association (1980) Diagnostic and Statistical Manual of Mental Disorders (3rd edn) (DSM-III). Washington, DC: APA.

- (1987) Diagnostic and Statistical Manual of Mental Disorders (3rd edn, revised) (DSM-III-R). Washington, DC: APA. 
- (1994) Diagnostic and Statistical Manual of Mental Disorders (4th edn) (DSM-IV). Washington, DC: APA

Beail, N. (1995) Outcome of psychoanalysis, psychoanalytic and psychodynamic psychotherapy with people with intellectual disabilities: a review. Changes, I3, |86-19|.

Bichard, S., Sinason, V. \& Usiskin, J. (1996) Measuring change in mentally retarded clients in long term psychoanalytic psychotherapy. The National Association for Dual Diagnosis, 13, 6-11.

Bonell-Pascual, E., Huline-Dickens, S., Hollins, S. et al (1999) Bereavement and grief in adults with learning disabilities. A follow-up study. British Journal of Psychiatry, 175, 348-350.

De Zulueta, F. (1993) From Pain to Violence: The Traumatic Roots of Destructiveness. London: Whurr.

Esterhuyzen, A. \& Hollins, S. (1997) Psychotherapy. In Psychiatry in Learning Disability (ed. S. Read), pp. 332-349. London: W. B. Saunders.

Frankish, P. (1989) Meeting the emotional needs of handicapped people: a psycho-dynamic approach. Journal of Mental Deficiency Research, 33, 407-414.

Freud, S. (1893) The psychical mechanism of hysterical phenomena. Reprinted (1953-1974) in the Standard Edition of the Complete Psychological Works of Sigmund Freud (trans. and ed. J. Strachey), Vol. 2, pp. 3-17. London: Hogarth Press.

Goldberg, D., Magrill, L., Hale, J., et al (1995) Protection and loss: working with learning disabled adults and their families. Journal of Family Therapy, I7, 263-280.

Harper, D. C. \& Wadsworth, J. S. (1993) Grief in adults with mental retardation: preliminary findings. Research in Developmental Disabilities, 14, 313-330.
Heal, M. (1989) In tune with the mind. In Mutud Respect: Therapeutic Approaches to Working with People who have Learning Difficulties (ed. D. Brandon), pp. 45-56. London: Good Impressions.

Hollins, S. \& Evered, C. (1990) Group process and content: the challenge of mental handicap. Group Analysis, 23, 55-67.

_ \& Esterhuyzen, A. (1997) Bereavement and grief in adults with learning disabilities. British Journal of Psychiatry, I70, 497-50I.

Hubert, J. (1991) Home Bound: Crisis in the Care of Young People with Severe Learning Difficulties: A Story of Twenty Families. London: King's Fund Centre.

Kroese, B. S., Dagnan, D. \& Loumidia, K. (eds) (1997) Cognitive Behaviour Therapy for People with Learning Disabilities. London: Routledge.

Lindsay, W. R. (1999) Cognitive therapy. The Psychologist, 12, 238-241.

Main, M. (1996) Introduction to the special section on attachment and psychotherapy: 2. Overview of the field of attachment. Journal of Consulting and Clinical Psychology, 64, 237-243.

Office of Population Censuses and Surveys (1989) Study of Disabled Children: Services, Transport and Education, Report 6. London: HMSO.

Oliver, C., Murphy, G. H. \& Corbett, J. A. (1987) Selfinjurious behaviour in people with mental handicap: total population study. Journal of Mental Deficiency Research, 31, 147-162.

Parry, G. (1993) NHS Review of Psychotherapy. London: HMSO.

Pynoos, R., Steinberg, A. \& Wraith, R. (1995) A developmental model of childhood traumatic stress. In Manual of Developmental Psychopathology, Vol. 2: Risk,
Disorder and Adaptation (eds D. Ciccetti \& D. J. Cohen), pp. 72-95. Chichester: John Wiley \& Sons.

Sausse, S. (1996) Le Miroir Brisé. L'enfant Hanidcapé, sa Famille et le Psychoanalyse. Paris: Calmann-Levy.

Scotti, J. R., Evans, E. M., Meyer, L. H., et al (199I) A meta-analysis of intervention research with problem behaviour: treatment, validity and standards of practice. American Journal of Mental Retardation, 96 233-256.

Sigman, M. (1985) Individual and group psychotherapy with mentally retarded adolescents. In Children with Emotional Disorders and Developmental Disabilities: Assessment and Treatment (ed. M. Sigman), pp. 259-277. Orlando, FL: Grune \& Stratton.

Sinason, V. (1986) Secondary mental handicap and its relationship to trauma. Psychoanalytic Psychotherapy, 2 |3|-|54.

- (1992) Mental Handicap and the Human Condition. London: Free Association Books.

Spitz, R. A. (1983) Dialogues from infancy. In Hospitalism: An Inquiry into the Genesis of Psychiatric Conditions in Early Childhood (ed. R. N. Emde), pp. 53-74. New York: International Universities Press.

Turk, J. (1998) Children with learning difficulties and their parents. In Cognitive-Behaviour Therapy for Children and Families (ed. P. Graham), pp. I10-125. Cambridge: Cambridge University Press.

— \& Brown, H. (1993) The sexual abuse of adults with learning disabilities: results of a two year incidence survey. Mental Handicap Research, 6, 193-216.

World Health Organization (1992) The $I C D-10$ Classification of Mental and Behavioural Disorders. Clinical Descriptions and Diagnostic Guidelines. Geneva: WHO. 